\title{
ON THE TWO-STEP PROJECTION METHODS AND APPLICATIONS TO VARIATIONAL INEQUALITIES
}

\author{
S. S. CHANG, Y. J. CHO AND J. K. KIM
}

Abstract. The purpose of this paper is, by using the two-step projection methods, to study the convergence analysis and the approximation solvability of the system of nonlinear variational inequalities in the setting of Hilbert spaces. The results presented in this paper generalize and improve the corresponding results in Verma [4].

Mathematics subject classification (2000): 47H05, 47H09, 49M05.

Key words and phrases: two-step projection method, system of nonlinear variational inequalities, $r$-strongly monotone mapping, $\mu$-Lipschitz mapping.

\section{REFERENCES}

[1] S. S. CHANG, Variational Inequality and Complementarity Problem Theory with Applications, Shanghai Sci. and Tech. Literature Publishers, Shanghai, 1991 (in Chinese).

[2] L. S. LIU, Ishikawa and Mann iterative process with errors for nonlinear strongly accretive mappings in Banach spaces, J. Math. Anal. Appl., 194, (1995), 114-127.

[3] RAM U. VERMA, Generalized class of partial relaxed monotonicity and its connections, Advan. in Nonlinear Variat. Inequal., 7, (2) (2004), 155-164.

[4] RAM U. VERMA, Generalized convergence analysis for two-step projection methods and applications to variational problems, Appl. Math. Lett., 18, (2005), 1286-1292. 